\title{
Seroprevalence of IgG Antibodies for Dengue among Blood Donors
}

\author{
Kavyasree Bandi ${ }^{1}$, Ravindra Prasad Thokala ${ }^{2}$, Ashwin Anandan ${ }^{3}$, \\ Krishnamoorthy Radhakrishnan ${ }^{4}$, Vinod Kumar Panicker ${ }^{5}$ \\ 1, 2, 3, 4, 5 Department of Transfusion Medicine, Sri Ramachandra Medical \\ College and Research Institute, Porur, Chennai, Tamil Nadu, India.
}

\section{ABSTRACT}

\section{BACKGROUND}

Dengue fever is endemic India and the prevalence of dengue is on the rise owing to various social and economic factors. Prevalence of asymptomatic dengue infection varies widely from less than $1 \%$ to $80 \%$ in India. Transfusion transmissible dengue has been reported in different parts of the word. Prevalence of subclinical dengue among blood donor poses a threat to the blood supply leading to transfusion transmissible dengue. We wanted to estimate the prevalence of IgG antibodies for Dengue in the blood donor population.

\section{METHODS}

Six hundred and eight whole blood donors were included in the study during the period January 2017 to October 2018. Donor registration and education was done as per the national guidelines. Donors who gave a history of previous dengue or symptoms consistent with dengue were excluded from the study. Serum samples from whole blood donors were tested for IgG antibodies using ELISA technology.

\section{RESULTS}

Of the total of 608 donors, 602 were male donors and $55 \%$ of the donors were in the age group 21 - 30 years. Majority (69\%) of the donors were from urban locations. Anti IgG antibodies for dengue were present in $4.14 \%$ of donors of which $38 \%$ of donors were in the age group 31 - 40 years. Three hundred and eighty-four donors revealed history of fever, myalgia and headache in the past one year. No statistical significance was found between fever, myalgia and the presence of $\operatorname{IgG}$ anti-dengue antibodies.

\section{CONCLUSIONS}

The subclinical or asymptomatic prevalence of dengue infection is low when compared to other studies in other parts of the country. Enquiring into donor history for history of dengue or symptoms of dengue and deferring such donors for a recommended period will prevent transfusion transmissible dengue.

\section{KEY WORDS}

Seroprevalence, Dengue IgG Antibodies, Subclinical Dengue, Blood Donors
Corresponding Author:

Dr. Ravindra Prasad Thokala.

Department of Transfusion Medicine, Sri

Ramachandra Medical College and

Research Institute, SRIHER, Porur, Chenai-

00116, Tamil Nadu, India.

E-mail: drravi1212@gmail.com

DOI: $10.14260 /$ jemds/2020/679

How to Cite This Article:

Bandi K, Thokala RP, Anandan A, et al. Seroprevalence of $\operatorname{IgG}$ antibodies for dengue among blood donors. J Evolution Med Dent Sci 2020; 9(42):3092-3096, DOI: 10.14260/jemds/2020/679

Submission 05-03-2020,

Peer Review 11-09-2020,

Acceptance 17-09-2020,

Published 19-10-2020.

Copyright (C) 2020 Kavya sree Bandi et al. This is an open access article distributed under Creative Commons Attribution License [Attribution 4.0 International (CC BY 4.0)] 


\section{BACKGROUND}

Dengue is a vector borne disease that is a global threat with endemicity in more than 100 countries and 50 million new infections are being added every year. Disease burden of dengue is on rise in India from 2001, a disease that was initially confined to northern and southern states has spread to many states now. Rise in temperature, urbanisation, changes in environmental factors together with inadequate vector control had contributed to the existing disease burden. ${ }^{1}$ The rate of asymptomatic or subclinical infection of dengue varied from less than $1 \%$ to $80 \%$ depending on the population studied. With increasing prevalence of dengue among the population, the blood recipient population is also at risk of acquiring dengue infection that can be subclinical in a majority of donor population. Dengue infection after solid organ transplantation, bone marrow transplantation and blood transfusion has been documented in a few studies. ${ }^{2,3}$

Arboviral disease transmission through blood products is a well-recognised fact. Spread of West Nile virus and chikungunya virus through blood transfusion has already been documented. The high prevalence of dengue in various regions, asymptomatic infection rate, the period of viremia, the high viral load and wide spread prevalence of the vector had placed dengue in the red category for emerging or re-emerging agents that could pose threat to blood supply in North America by AABB (American Association of Blood Bank). ${ }^{4}$ The potential of dengue to emerge as a threat to blood safety is recognised even in European countries that has not documented autochthonous dengue infection since 1930.5 In India the prevalence of dengue infection varied with population studied with some parts having a prevalence rate of over $50 \% .{ }^{6}$ And in some parts of the country where the prevalence is close to zero among donor population. ${ }^{7}$ Prevalence of subclinical infection among donor population in middle east has also been observed. ${ }^{8}$

The disease burden of dengue is higher in India owing to the favourable conditions existing like the tropical climate, changing climate, increased temperature, and abundance of vectors, migrating population and inadequate vector control measures.9,10 Dengue infection can remain subclinical and viremia in the subclinical phase can transmit dengue infection through blood collected during this phase. ${ }^{11}$ Studies on prevalence of dengue in blood donor population are limited from this part of the country, hence this study was done to determine the subclinical prevalence of dengue infection among healthy voluntary blood donors.

\section{METHODS}

This cross-sectional study was carried out after Institutional Ethics Committee approval. Serum samples from 608 whole (the sample size included was based on the number of donors with inclusion criteria who walked in to donate blood during the study period and the number of assay kits procured to analyse the samples) blood donors collected during the period January 2017 to October 2018 were included in the study, whole blood donors representing all parts of the state were tested for dengue specific IgG antibodies using ELISA after obtaining informed consent. Voluntary donors walking in to the blood bank were screened using a donor screening questionnaire. Additional information regarding dengue infections was enquired and recorded by the examining medical officer. Donors who revealed history of dengue infection in the past were excluded from the study. Donors who revealed symptoms consistent with symptoms of dengue in the past were also excluded from the study. Donors who revealed history of fever with symptoms not specifically attributable to dengue infection were included in the study.

Serum samples collected in pilot tubes for mandatory transfusion transmissible infection (TTI) screening were used for this study after the completion of mandatory TTI screening. These serum samples were tested for dengue specific IgG antibodies in a fully automated Elisa platform (EVOLISTM, BioRad, using GAC-Capture ELISA kit). All samples were processed within 72 hours of collection and the results were recorded after verifying the validation criteria of a particular run. Results were interpreted according to the manufacturer instructions. If the dengue IgG units is $<9$, then the result was interpreted as negative for dengue IgG antibodies, if dengue IgG units was between 9 - 11, then the result is interpreted as equivocal for dengue IgG antibodies, if dengue IgG units is $>11$, then the result was interpreted as positive for dengue $\operatorname{IgG}$ antibodies.

\section{Statistical Analysis}

Data was analysed using descriptive statistics. The unpaired ttest was employed to analyse continuous variables. Chi-Square Test and Fisher Exact Test was employed for categorical variables. Statistical significance was taken as $p<0.05$. The data was analysed using SPSS version 16 .

\section{RESULTS}

Six hundred and eight donor samples were tested for dengue IgG antibodies. Of the total 608 donors included in the study there were only 6 female donors and 602 male donors. Majority of the donors (55\%) belonged to age group of 21 - 30 years of age (Figure 1). Donors representing urban population were $69 \%$ and rural side were $31 \%$. Among the total sample population, Dengue IgG antibodies were present in $4.14 \%$ of blood donors and $95.86 \%$ of blood donors were negative for anti-dengue IgG antibodies.

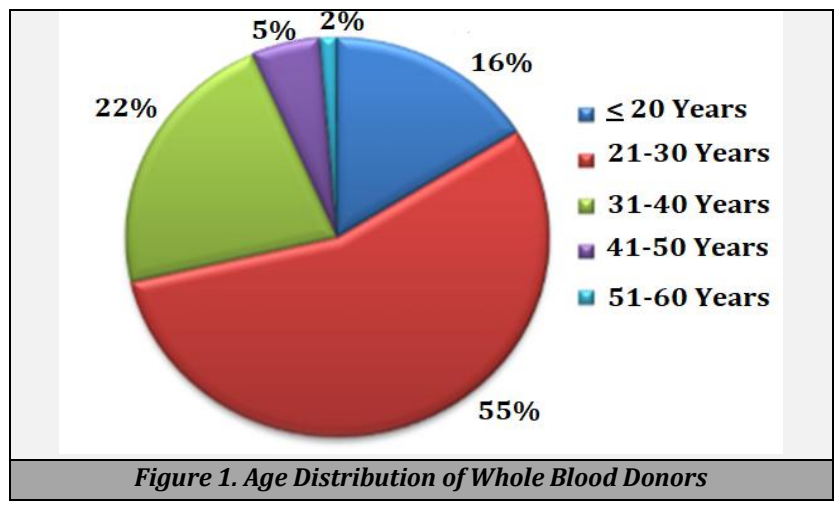

It is evident from Table 1 that most of the IgG positive blood donors were in 31 - 40 years age group (38.46\%) with 
a mean age of 29.31 years. In IgG negative group most were in 21 - 30 years age group (56.36\%) with a mean age of 27.45 years. $(p=0.387)$. The data subjected to unpaired t-test reveals the existence of statistically non-significant association between age distribution and anti-dengue IgG prevalence $(p>0.05)$.

\begin{tabular}{|c|c|c|c|c|c|c|}
\hline $\begin{array}{c}\text { Age } \\
\text { Distributi } \\
\text { on - } \\
\text { Groups }\end{array}$ & $\begin{array}{l}\text { No. of } \\
\text { Donors }\end{array}$ & $\begin{array}{c}\text { IgG } \\
\text { Positive }\end{array}$ & $\begin{array}{c}\text { IgG } \\
\text { Positive } \\
\%\end{array}$ & $\begin{array}{c}\text { IgG } \\
\text { Negative }\end{array}$ & $\begin{array}{c}\text { IgG } \\
\text { Negative } \\
\%\end{array}$ & $\begin{array}{l}\% \text { of Age } \\
\text { Group among } \\
\text { Total Donors }\end{array}$ \\
\hline$\leq 20$ years & 98 & 6 & 23.08 & 92 & 15.81 & 16.12 \\
\hline $\begin{array}{c}21-30 \\
\text { years }\end{array}$ & 336 & 8 & 30.77 & 328 & 56.36 & 55.26 \\
\hline $\begin{array}{c}31-40 \\
\text { years }\end{array}$ & 134 & 10 & 38.46 & 124 & 21.31 & 22.04 \\
\hline $\begin{array}{l}41-50 \\
\text { years }\end{array}$ & 32 & 2 & 7.69 & 30 & 5.15 & 5.26 \\
\hline $\begin{array}{c}51-60 \\
\text { years }\end{array}$ & 8 & 0 & 0.00 & 8 & 1.37 & 1.32 \\
\hline Total & 608 & 26 & 100.00 & 582 & 100.00 & 100.00 \\
\hline \multicolumn{7}{|c|}{$\mathrm{p}$ value } \\
\hline
\end{tabular}

As the number of female's donors were less than $1 \%$, statistically non-significant association was observed between gender status and anti-dengue IgG prevalence ( $p>0.05$ ). It is evident from the area of living status table (Table 2) that most of the IgG positive group subjects $(n=20)$ belonged to corporation area $(76.92 \%)$ and in IgG negative group too majority belonged to corporation area $(68.73 \%)(p=0.761)$. This data subjected to Fishers Exact test reveals the existence of statistically non-significant association between area of living status and IgG study groups $(\mathrm{p}>0.05)$.

\begin{tabular}{|c|c|c|c|c|c|c|}
\hline $\begin{array}{l}\text { Area of Living } \\
\text { - Groups }\end{array}$ & $\begin{array}{c}\text { IgG } \\
\text { Positive }\end{array}$ & $\begin{array}{c}\text { IgG } \\
\text { Positive } \\
\%\end{array}$ & $\begin{array}{c}\text { IgG } \\
\text { Negative }\end{array}$ & $\begin{array}{c}\text { IgG } \\
\text { Negative } \\
\%\end{array}$ & Total & $\%$ \\
\hline Corporation Area & 20 & 76.92 & 400 & 68.73 & 420 & 69.08 \\
\hline $\begin{array}{c}\text { Non Corporation } \\
\text { Area }\end{array}$ & 6 & 23.08 & 182 & 31.27 & 188 & 30.92 \\
\hline Total & 26 & 100.00 & 582 & 100.00 & 304 & 100.00 \\
\hline \multicolumn{3}{|c|}{$\mathrm{p}$ value } & \multicolumn{4}{|c|}{0.761} \\
\hline
\end{tabular}

Three hundred and eighty four Blood donors revealed symptoms like fever, myalgia, headache and vomiting in the past one year (Figure 2). These donors did not have serologically confirmed diagnosis of dengue or any other viral or bacterial illness. These donors did not require hospital admission and were treated either by their family physician on outpatient basis or took self-medication and recovered.

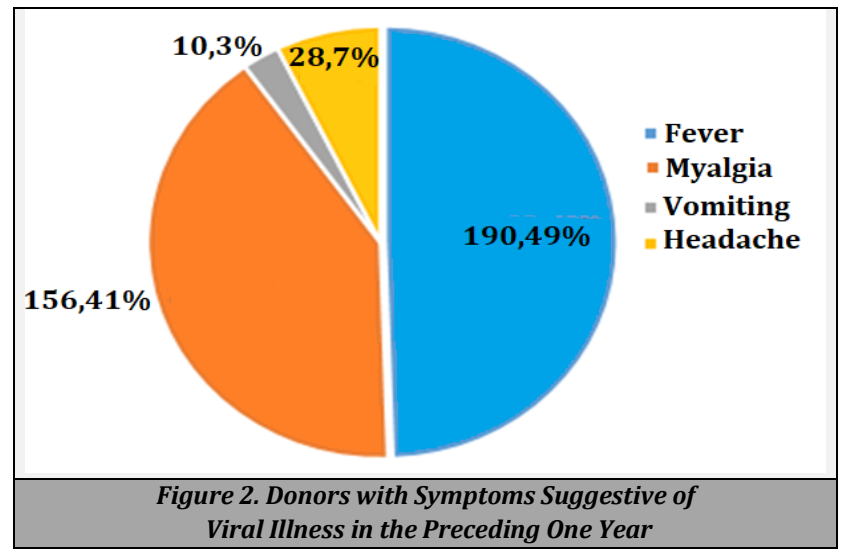

Among the 26 donors reactive for anti-dengue IgG antibodies (Table 3), 18 donors revealed history of fever, 16 donors revealed history of myalgia and 2 revealed history of vomiting and none of them reported history of rashes and headache. Of the donors who were negative for IgG dengue $n=$ 582, 172 donors revealed history of fever, 140 donors revealed history of myalgia, 8 donors revealed history of vomiting, 28 donor revealed history of headache.

\begin{tabular}{|c|c|c|c|c|c|c|c|}
\hline $\begin{array}{c}\text { Symptoms } \\
\text { - Groups }\end{array}$ & $\begin{array}{c}\text { IgG } \\
\text { Positive }\end{array}$ & $\%$ & $\begin{array}{c}\text { IgG } \\
\text { Negativ } \\
\text { e }\end{array}$ & $\%$ & Total & $\%$ & $\begin{array}{c}\text { P Value } \\
\text { Fishers Exact } \\
\text { Test }\end{array}$ \\
\hline Fever & 18 & 69.23 & 172 & 29.55 & 190 & 31.25 & 0.003 \\
\hline Myalgia & 16 & 61.54 & 140 & 24.05 & 156 & 25.66 & 0.006 \\
\hline Vomiting & 2 & 3,84 & 8 & 1.3 & 20 & 3.29 & 0.062 \\
\hline Headache & 0 & 0.00 & 28 & 4.81 & 28 & 4.61 & $>0.999$ \\
\hline
\end{tabular}

The data in Table 3, subjected to Fishers Exact test reveals the existence of statistically significant association between fever, and myalgia status and IgG study groups ( $\mathrm{p}<0.05)$. Similarly when data was subjected to fishers exact test it reveals the existence of statistically non-significant association between vomiting and headache status and IgG study groups $(\mathrm{p}>0.05)$

Logistic regression model for statistically significant independent predictors of having IgG antibodies against dengue virus risk factors when performed, found no significant association between the age, gender, area of living and symptoms suggestive of dengue in past one year.

\section{DISCUSSION}

In a study from New Delhi, in the northern part of the country, among a population of 200 donors tested, $58 \%$ of the donors had a reactive test for IgG antibodies, when these donors were tested for the presence of virus using RT-PCR, none of the donors had detectable viremia. ${ }^{6}$

A study from northern India in 2013, where 1709 whole blood donations were tested for presence of NS1 antigen, the prevalence of NS1 was found to be zero. In this study donors were representative of the patient population suffering from dengue. ${ }^{7}$ As this study was aimed at detecting NS1 that is present in the acute phase of the dengue illness, it is only logical that anyone with fever or with the symptoms of viral illness would not have turned up for blood donation.

In a study conducted across six distinct geographic location across India during the period 2011 - 2012, samples from 2609 healthy children aged 5 - 10 years were tested for dengue IgG antibodies. A high prevalence rate of $56 \%$ was recorded in this study. This study revealed that the disease burden of dengue in India is comparable to disease burden of Southeast Asian and Latin American countires. ${ }^{12}$ Similarly another study from Andhra Pradesh revealed a high prevalence (89.5\%) of dengue IgG antibodies among apparently healthy people who visited hospital for Master Health Check-up. ${ }^{13}$ A prevalence study done in 2017 post dengue surge in 2016 in Pune among 1434 individuals covering men, women and children revealed a prevalence of $81 \%$ for dengue specific IgG antibodies. ${ }^{14}$

A study from Chennai with a sample size of 1010 general population the prevalence of IgG specific dengue antibodies was found to be $93 \%$ indicating that $93 \%$ of the sample 
population had a previous dengue infection whereas only $1 \%$ revealed a history of dengue infection indicating a high percentage subclinical infection. ${ }^{15}$ In another study from the country's capital New Delhi, 2125 individual households who were living around 50 confirmed dengue cases were tested for dengue specific antibodies which revealed a prevalence of 36 $\%$ for dengue specific IgG antibodies. ${ }^{16}$

On comparison with other studies, ${ }^{12-16}$ the prevalence of IgG antibodies in the blood donors is as low as $4.14 \%$. In this present study. In the other studies mentioned above the sample population included in the study were general population without apparent disease, whereas in our study the sample population included are healthy donors in whom history of dengue and other history of symptoms consistent with viral illness has been elicited. Donors who gave history of dengue in past and donors who revealed symptoms consistent with dengue were excluded from this study. Such an exclusion criteria of this study would reveal the true subclinical infection burden of dengue among blood donor population.

In this study, the prevalence of dengue IgG antibodies is low, (4.14 \%) as compared to a similar study from north India where a high prevalence of $58 \%$ has been recorded. A study on the prevalence of asymptomatic dengue infection among blood donors from Australia, Hondorus and Brazil revealed a prevalence of $0.3 \%$ in Honduras to 0.04 in Brazil. ${ }^{17}$ A study from Taiwan in 2015 tested eight thousand samples for dengue viremia NS1 and anti-dengue IgM and IgG antibodies revealed very low prevalence rate of $0 \%, 0.21 \%$ and $0.16 \%$ respectively. ${ }^{18} \mathrm{~A}$ study from Brazil on transfusion transmitted dengue in year 2012 revealed a dengue viremia prevalence of less than $1 \%$ among the blood donors. ${ }^{19}$

The prevalence of viremia as demonstrated by detecting dengue viral RNA has revealed prevalence of less than $1 \%$ among blood donors.[17-19] The period of viremia had been observed until day 8 on average for all the four serotypes. The period of NS1 antigenemia, on average lasts until day 9 in most of the reported cases. ${ }^{20}$ There are only a few cases reported for transfusion transmissible dengue ${ }^{3}$ as the period of viremia and antigenemia resolve after the period of acute illness.

Studies Conducted in Malaysia ${ }^{21}$ and Singapore ${ }^{22}$ during the period 2009 - 2010, both places were endemic for dengue revealed a high prevalence of dengue IgG antibodies of $46 \%$ and $50 \%$ respectively. When compared to similar studies on blood donors ${ }^{5,6}$ the prevalence of anti-dengue IgG were less in this study as donors with previous dengue infection, donors who revealed history of symptoms consistent with dengue were excluded from the study. Such an exclusion would reveal the true subclinical infection prevalence among blood donors.

\section{Limitation}

IgG positive donors were not evaluated for the presence of antigen or for presence of the virus and the infectivity of donor blood unit at this point cannot be commented upon.

\section{CONCLUSIONS}

Prevalence of dengue infection is increasing in India with the prevalence increasing with age. Social, climatic and economic conditions combined with lack of vaccine are factors largely favouring the spread of the disease. Transfusion transmitted dengue though reported in clusters in few parts of the world, its incidence is very less. Prevalence of subclinical dengue infection is less when compared to similar studies from other parts of the country. When prospective blood donors are examined for history of dengue infection and for symptoms consistent with dengue, deferring such donors for the recommended deferral period of 6 months would largely prevent transfusion transmissible dengue.

Data sharing statement provided by the authors is available with the full text of this article at jemds.com.

Financial or other competing interests: None.

Disclosure forms provided by the authors are available with the full text of this article at jemds.com.

\section{REFERENCES}

[1] Mutheneni SR, Morse AP, Caminade C, et al. Dengue burden in India: recent trends and importance of climatic parameters. Emerg Microbes Infect 2017; 6(8):e70.

[2] Teo D, Ng LC, Lam S. Is dengue a threat to the blood supply? Transfus Med 2009; 19(2):66-77.

[3] Rooks K, Seed CR, Fryk JJ, et al. mitigating the risk of transfusion-transmitted dengue in Australia. J Blood Transfus 2016; 2016:3059848.

[4] Pozzetto B, Memmi M, Garraud O. Is transfusiontransmitted dengue fever a potential public health threat? World J Virol 2015; 4(2):113-23.

[5] Schmidt M, Geilenkeuser WJ, Sireis W, et al. Emerging pathogens - how safe is blood? Transfus Med Hemother 2014; 41(1):10-7.

[6] Ranjan P, Natarajan V, Bajpai M, et al. High seroprevalence of dengue virus infection in blood donors from Delhi: a single centre study. J Clin Diagn Res 2016; 10(10):DC0810.

[7] Mangwana S. Dengue viremia in blood donors in Northern India: challenges of emerging dengue outbreaks to blood transfusion safety. Asian J Transfus Sci 2015; 9(2):177-80.

[8] Ashshi AM. Serodetection of dengue virus and its antibodies among blood donors in the western region of Saudi Arabia: a preliminary study. Blood Transfus 2015; 13(1):135-8.

[9] Ganeshkumar P, Murhekar MV, Poornima V, et al. Dengueinfection in India: a systematic review and metaanalysis. PLoS Negl Trop Dis 2018; 12(7):e0006618.

[10] Sahanaa C, Mishra AK, Bazroy J. Trend of morbidity and mortality of dengue in Tamil Nadu and Puducherry, South India. Int J Community Med Public Health 2018; 5(1):3225.

[11] Wilder-Smith A, Chen LH, Massad E, et al. Threat of dengue to blood safety in dengue-endemic countries. Emerg Infect Dis 2009; 15(1):8-11.

[12] Garg S, Chakravarti A, Singh R, et al. Dengue serotypespecific seroprevalence among 5- to 10-year-old children in India: a community-based cross-sectional study. Int J Infect Dis 2017;54:25-30.

[13] Oruganti G, Dinaker M, Tez KSRS, et al. High seroprevalence of dengue IgG antibodies among healthy individuals in Andhra Pradesh, India. Indian Journal of Public Health Research and Development 2014; 5(1):1315. 
[14] Mishra AC, Arankalle VA, Gadhave SA, et al. Stratified sero-prevalence revealed overall high disease burden of dengue but suboptimal immunity in younger age groups in Pune, India. PLoS Negl Trop Dis 2018; 12(8):e0006657.

[15] Rodriguez-Barraquer I, Solomon SS, Kuganantham P, et al. The hidden burden of dengue and chikungunya in Chennai, India. PLOS Negl Trop Dis 2015; 9(7):e0003906.

[16] Vikram K, Nagpal BN, Pande V, et al. An epidemiological study of dengue in Delhi, India. Acta Trop 2016; 153:21-7.

[17] Linnen JM, Vinelli E, Sabino EC, et al. Dengue viremia in blood donors from Honduras, Brazil, and Australia. Transfusion 2008; 48(7):1355-62.

[18] Tsai JJ, Lin PC, Tsai CY, et al. Low frequency of asymptomatic dengue virus-infected donors in blood donor centres during the largest dengue outbreak in Taiwan. PLoS One 2018; 13(10):e0205248.
[19] Sabino EC, Loureiro P, Lopes ME, et al. Transfusiontransmitted dengue and associated clinical symptoms during the 2012 epidemic in Brazil. J Infect Dis 2016:213(5):694-702.

[20] Tricou V, Minh NN, Farrar J, et al. Kinetics of viremia and NS1 antigenemia are shaped by immune status and virus serotype in adults with dengue. PLoS Negl Trop Dis 2011; 5(9):e1309.

[21] Harif NF, Kader ZSA, Joshi SR, et al. Seropositive status of dengue virus infection among blood donors in North Malaysia. Asian J Transfus Sci 2014; 8(1):64.

[22] Low SL, Lam S, Wong WY, et al. Dengue seroprevalence of healthy adults in Singapore: serosurvey among blood donors, 2009. Am J Trop Med Hyg 2015; 93(1):40-5. 